\title{
Immunohistological features of synovitis in ankylosing spondylitis: a comparison with rheumatoid arthritis
}

\author{
B L KIDD, K MOORE, M T WALTERS, J L SMITH, AND M I D CAWLEY
}

From the Rheumatology Unit, and the Wessex Regional Immunology Service, Southampton General Hospital, Southampton

SUMMARY The immunohistological features of the synovial membrane in ankylosing spondylitis, HLA-B27 associated oligoarthritis, and rheumatoid arthritis were examined with particularoo reference to $\mathrm{T}$ lymphocyte subsets. T helper $(\mathrm{CD} 4+)$ cells clearly outnumbered $\mathrm{T}$ suppressor $\mathrm{i}_{0}^{0}$ cytotoxic $(\mathrm{CD} 8+)$ cells in rheumatoid arthritis, whereas both cell types were present in equaN numbers in ankylosing spondylitis. A reduction of CD4+/CD45R + suppressor/inducer cells relative to CD4+/UCHL1+ helper/inducer cells was apparent in all diagnostic groups. The $\vec{T}$ observations were suggestive of disease specific inflammatory responses within synovia品 membrane.

Key words: synovial membrane, $\mathrm{T}$ lymphocytes.

Inflammation within the synovial membrane of peripheral joints occurs in both rheumatoid arthritis (RA) and ankylosing spondylitis (AS). Routine histological and more recent immunohistological studies have failed to show major differences between the two disorders. ${ }^{1-5}$

Clinically and serologically the two disorders are readily distinguishable. RA classically affects the synovial membrane of peripheral small joints and has a progressive and destructive disease course. In contrast, the primary lesion in AS appears to be at the enthesis, peripheral joint involvement usually being episodic and non-destructive, and most commonly involving the larger joints of the lower limb. ${ }^{6}$ Although widespread systemic disturbances including production of rheumatoid factor are apparent in RA, no such features have been reported in AS, where there appears to be a much more localised disturbance. ${ }^{?}$

Histological examination of RA involved synovial membrane has shown that the mononuclear cell infiltrate consists predominantly of $\mathrm{T}$ lymphocytes. Given the central role of $T$ lymphocytes in the immune response,${ }^{8}$ abnormalities within $\mathrm{T}$ cell populations may prove to be sensitive indicators of disease mechanisms. We have therefore re-examined

Accepted for publication 14 June 1988.

Correspondence to Dr B L Kidd, Rheumatology Unit, Southampton General Hospital, Tremona Road, Southampton SO9 4XY.
Table 1 Clinical characteristics

\begin{tabular}{|c|c|c|c|c|c|}
\hline Subject & Age/sex & $\begin{array}{l}\text { Disease } \\
\text { duration } \\
\text { (years) }\end{array}$ & $\begin{array}{l}\text { Rheumatoid } \\
\text { factor } \\
(S C A T)^{*}\end{array}$ & $B 27$ & $\begin{array}{l}E S R^{*} \\
(\mathrm{~mm} / \mathrm{h}\end{array}$ \\
\hline \multicolumn{6}{|c|}{ Rheumatoid arthritis } \\
\hline 1 & $62 / \mathrm{F}$ & 2 & $1 / 512$ & - & 58 \\
\hline 2 & $60 / \mathrm{M}$ & 1 & $1 / 40$ & - & 70 \\
\hline 3 & 48/M & 4 & $1 / 640$ & - & 74 \\
\hline 4 & $57 / \mathrm{F}$ & 5 & - & - & 115 \\
\hline 5 & $65 / \mathrm{F}$ & 8 & $1 / 512$ & - & 118 \\
\hline 6 & $67 / F$ & 15 & $1 / 80$ & - & 86 \\
\hline 7 & $61 / F$ & 8 & $1 / 1024$ & - & 93 \\
\hline 8 & $54 / F$ & 3 & $1 / 320$ & - & 54 \\
\hline 9 & $52 / \mathbf{F}$ & 1 & $1 / 1280$ & - & 50 \\
\hline 10 & $48 / \mathrm{M}$ & 3 & $1 / 640$ & - & 95 \\
\hline \multicolumn{6}{|c|}{ Ankylosing spondylitis } \\
\hline 11 & $57 / \mathrm{M}$ & 31 & - & + & 36 \\
\hline 12 & 29/M & 9 & - & + & 2 \\
\hline 13 & $41 / \mathrm{M}$ & 6 & - & + & 56 \\
\hline 14 & $29 / \mathrm{M}$ & 6 & - & + & 18 \\
\hline 15 & $31 / \mathrm{M}$ & 14 & - & + & 1 \\
\hline 16 & $67 / \mathrm{F}$ & 26 & - & + & 11 \\
\hline 17 & $46 / M$ & 27 & - & + & 18 \\
\hline 18 & $26 / M$ & 16 & - & + & NA \\
\hline 19 & $30 / \mathrm{M}$ & 10 & - & + & 2 \\
\hline 20 & $54 / F$ & 11 & - & + & 4 \\
\hline \multicolumn{6}{|c|}{ Oligoarthritis } \\
\hline 21 & $68 / \mathrm{M}$ & 10 & - & + & 20 \\
\hline 22 & $31 / \mathrm{F}$ & 4 & - & + & 25 \\
\hline
\end{tabular}

${ }^{*}$ SCAT $=$ sheep cell agglutination titre; ESR=erythrocyte sedi을 mentation rate. 
the synovial membrane in RA and AS using immunohistological methods with particular reference to $\mathrm{T}$ lymphocyte subsets in order to determine whether apparent differences in aetiopathogenesis can be identified at tissue level.

\section{Patients and methods}

Twenty two patients were recruited from those

Table 2 Monoclonal antibodies used in this study

\begin{tabular}{llll}
\hline $\begin{array}{l}\text { Monoclonal } \\
\text { antibody }\end{array}$ & Specificity & Reference \\
\hline WR6 & (CD45) & Pan leucocyte & 14 \\
UCHT1 & (CD3) & Mature T lymphocyte & 14 \\
Leu3a & (CD4) & T helper/inducer & 14 \\
OKT8 & (CD8) & T suppressor/cytotoxic & 14 \\
UCHL1 & & Helper/inducer & 15 \\
WR16 & (CD45R) & Suppressor/inducer & 16 \\
Leu7a & & Natural killer cells & 17 \\
W6/32 & & HLA class 1 & 18 \\
WR18 & & HLA class 2 & \\
& (DP+DQ+DR B chains) & 19 \\
3.9 & (CD11c) & Macrophage (a chain LFA) & 14 \\
Ki67 & & Proliferating cell & 20 \\
\hline
\end{tabular}

attending the rheumatology unit of Southampton General Hospital. Ten of these fulfilled the American Rheumatism Association criteria for classical or definite RA. ${ }^{9}$ Ten other patients were HLA-B27 positive and fulfilled the modified New York criteria for $\mathrm{AS}^{10}$ One of these subjects had coexistent psoriasis. The remaining two patients were HLA-B27 positive with a seronegative nondestructive oligoarthritis and enthesitis but did not fit clearly within the spectrum of the generally accepted spondarthritic disease groups. ${ }^{11}$ All patients were selected on the basis of having received only analgesics or non-steroidal anti-inflammatory drugs as treatment for their rheumatic complaint. Table 1 summarises the clinical details.

Synovial biopsy specimens were taken from the midline of the suprapatellar pouch of a clinically inflamed knee with a Cope pleural biopsy needle. Specimens were immediately snap frozen and subsequently stored in liquid nitrogen.

An indirect immunoperoxidase method employing 3-amino 9-ethylcarbazole as chromogen was used to identify cells on serial $5 \mu \mathrm{m}$ cryostat sections as previously described. ${ }^{12} 13$ Table 2 summarises the monoclonal antibodies used in the study.

Table 3 Principal immunohistological findings in synovial membrane

\begin{tabular}{|c|c|c|c|c|c|c|c|}
\hline \multirow[t]{2}{*}{ Subject } & \multirow{2}{*}{$\begin{array}{l}\text { Density of } \\
\text { infiltrate** }\end{array}$} & \multicolumn{6}{|c|}{ Synovial cell fractions ${ }^{\dagger}$} \\
\hline & & $C D 3$ & $C D 4$ & $C D 8$ & $U C H L I$ & WR16 & Ki67 \\
\hline \multicolumn{8}{|c|}{ Rheumatoid arthritis } \\
\hline 1 & 3 & 3 & 2 & 1 & 2 & 1 & 1 \\
\hline 2 & 3 & 4 & 3 & 1 & 3 & 1 & 1 \\
\hline 3 & 2 & 2 & 2 & 1 & 3 & 1 & $i$ \\
\hline 4 & 3 & 4 & 3 & 1 & 3 & 1 & 1 \\
\hline 5 & 2 & 3 & 3 & 1 & 3 & 1 & 1 \\
\hline 6 & 3 & 3 & 3 & 1 & 3 & 1 & 1 \\
\hline 7 & 1 & 3 & 3 & 1 & 2 & 1 & 1 \\
\hline 8 & 2 & 3 & 2 & 1 & 3 & 1 & 1 \\
\hline 9 & 3 & 3 & 3 & 2 & 3 & 1 & 1 \\
\hline 10 & 2 & 2 & 2 & 2 & 3 & 1 & 1 \\
\hline \multicolumn{8}{|c|}{ Ankylosing spondylitis } \\
\hline 11 & 3 & 4 & 2 & 2 & 3 & 1 & 2 \\
\hline 12 & 3 & 3 & 3 & 2 & 3 & 2 & 2 \\
\hline 13 & 2 & 3 & 2 & 2 & 2 & 1 & 2 \\
\hline 14 & 1 & 3 & 2 & 2 & 2 & 1 & 1 \\
\hline 15 & 1 & 2 & 1 & 1 & 2 & 1 & 1 \\
\hline 16 & 2 & 4 & 2 & 2 & 2 & 1 & 1 \\
\hline 17 & 3 & 4 & 2 & 2 & 2 & 1 & 1 \\
\hline 18 & 2 & 3 & 2 & 2 & 2 & 1 & 1 \\
\hline 19 & 3 & 3 & 2 & 2 & 2 & 1 & 2 \\
\hline 20 & 1 & 2 & 1 & 1 & 3 & 1 & 1 \\
\hline \multicolumn{8}{|c|}{ Oligoarthritis } \\
\hline 21 & 3 & 3 & 2 & 2 & 3 & 1 & 2 \\
\hline 22 & 2 & 2 & 1 & 1 & 2 & 2 & 1 \\
\hline
\end{tabular}

*Density: $1=$ mild; 2 =moderate; $3=$ heavy.

tCell fractions: $1=$ few; $2=$ less than half; $3=$ more than half; $4=$ most cells positive. 
94 Kidd, Moore, Walters, Smith, Cawley

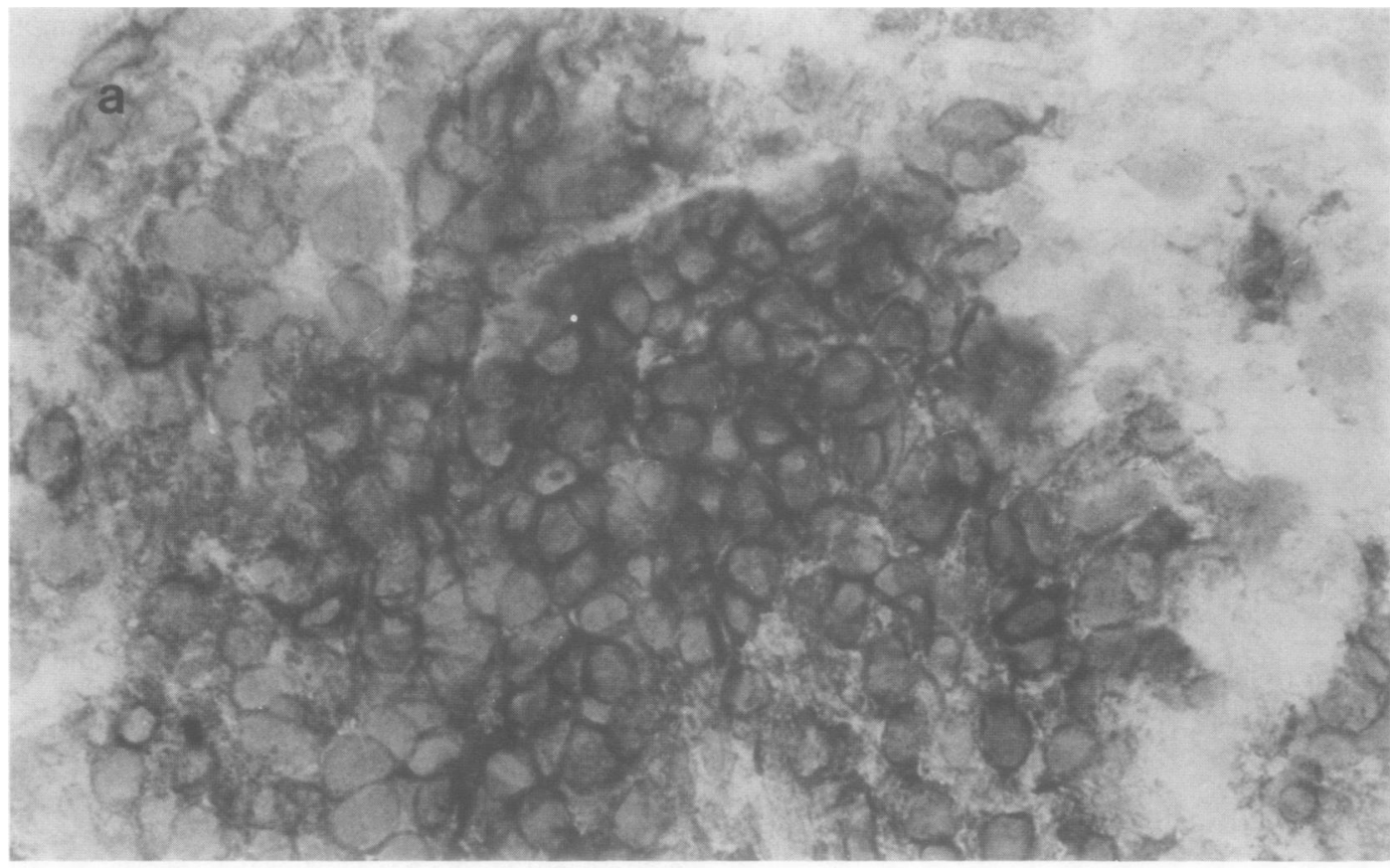

Fig. 1a

Fig. 1 Serial synovial membrane sections from patients with rheumatoid arthritis stained for (a) Leu3a (CD4) and (b) OKT8 (CD8), showing increased numbers of CD4+ cells relative to CD8+ cells. (Immunoperoxidase). 


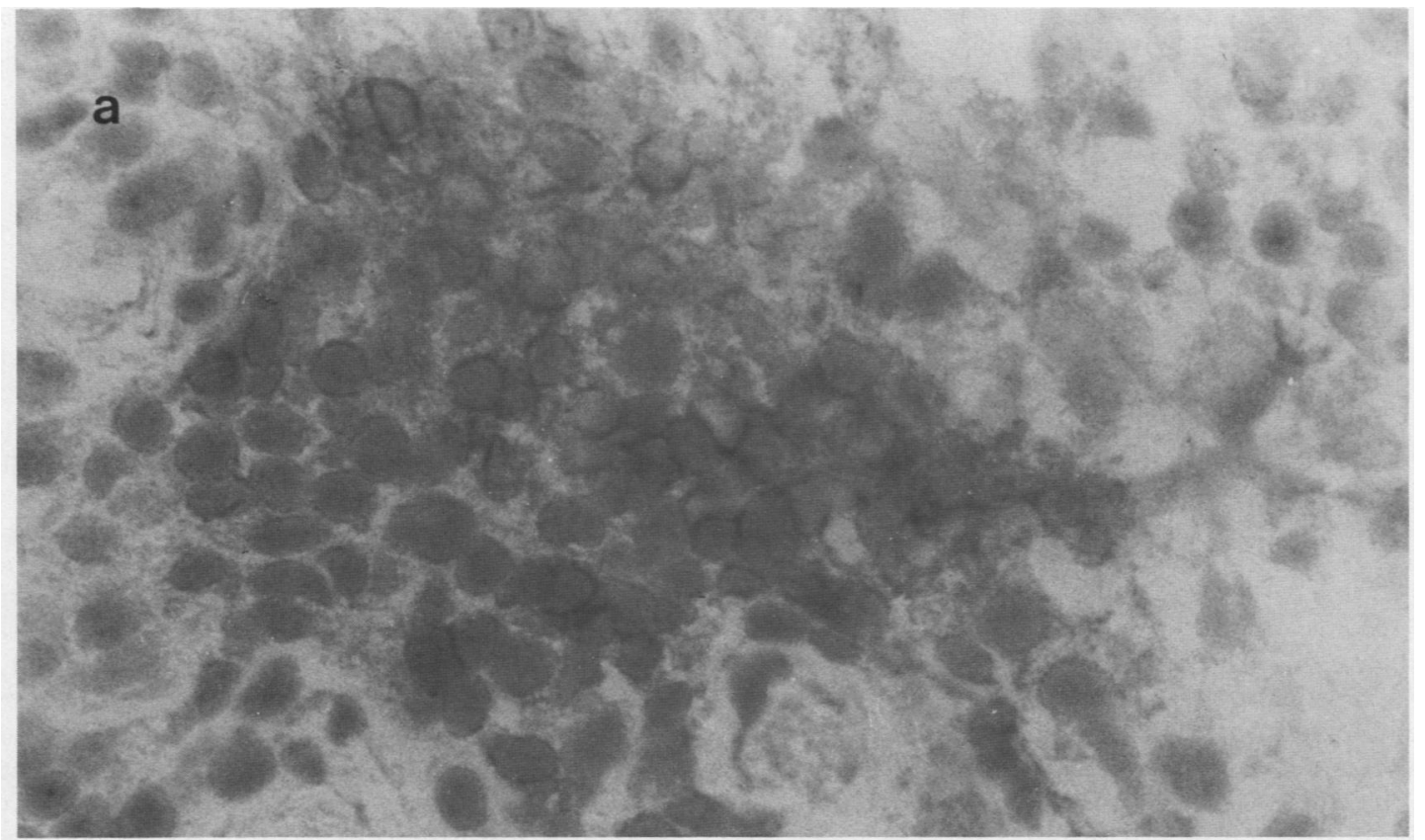

Fig. 2a

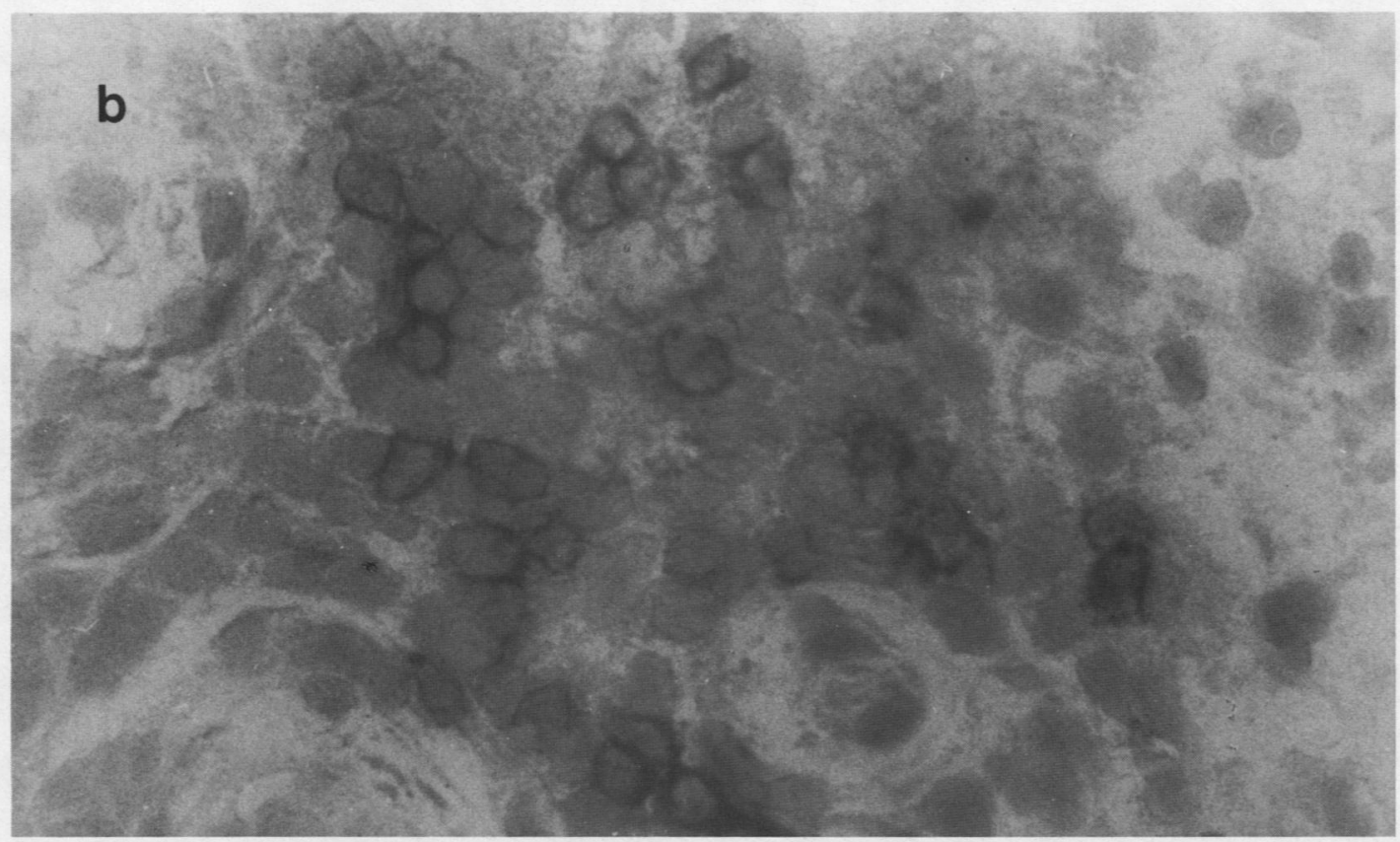

Fig. 2b

Fig. 2 Serial synovial membrane sections from patients with ankylosing spondylitis stained for (a) Leu3a (CD4) and (b) OKT8 (CD8), showing similar numbers of CD4+ and CD8+ cells. 
The synovial membrane sections were read independently in a blind fashion by two observers. General histological features of each biopsy specimen were assessed using an haematoxylin-eosin stain and, in particular, note was taken of the pattern of cellular infiltrate. Density of infiltrate was scored on a 1 to 3 basis depending on whether the infiltrate was mild, moderate, or marked. Individual monoclonal antibody stains were assessed in serial sections using a five point scale: $0=$ no cells present, $1=$ few positive cells, $2=$ less than half cells positive, $3=$ more than half cells positive, $4=$ all or nearly all cells positive. An overall score was recorded for each biopsy specimen, although note was taken of any regional variation.

\section{Results}

Table 3 shows the principal immunohistological findings in synovial membrane.

Marked variation in the pattern and density of the cellular infiltrate was noted, using haematoxylineosin stains, between individual biopsy specimens, though no overall differences were observed between biopsy specimens taken from subjects with rheumatoid arthritis and those with ankylosing spondylitis. Most specimens showed a diffuse inflammatory infiltrate, but a minority had patchy infiltrates surrounded by areas of extensive fibrosis. Increased vascularity was found in most biopsy specimens, and distinct aggregates of lymphoid cells were observed in AS as well as RA.

A heavy T cell $(\mathrm{CD} 3+)$ infiltrate occurred in both diseases. There was a marked increase in CD4+ lymphocyte subsets over CD8+ lymphocyte subsets in RA, and it was apparent that the greatest imbalance between the two subsets occurred in the perivascular regions (Figs $1 \mathrm{a}$ and $\mathrm{b}$ ).

In the biopsy specimens taken from subjects with AS and oligoarthritis both CD4+ and CD8+ subsets were present in equal proportions in all regions (Figs 2a and $b$ ).

Cells positive for Ki67, a monoclonal antibody which identifies a human nuclear antigen present in proliferating cells but absent in resting cells, ${ }^{20}$ were more common in AS and were most numerous in areas corresponding to the highest concentration of CD3+ cells.

In both diseases there was a gross excess of UCHL1+ cells compared with CD45R + cells.

No other significant differences were observed between the groups. Only a few Leu7+ cells were found in any of the biopsy specimens. Large numbers of macrophages (CD11c+) were present in all biopsy specimens. There was heavy expression of HLA class I and class II in all groups, class II expression being mainly confined to CD3 + cells and macrophages, whereas class I was more widely expressed, particularly around endothelial tissue.

\section{Discussion}

Although our findings suggest significant immunohistological differences between RA and AS, consideration should be given to several factors which may have influenced the results. Firstly, disease duration varied considerably between individual patients and tended to be longer in AS. The disease process in AS, however, tends to be more episodic than in RA, and most of the AS biopsy specimens were obtained from joints where an exacerbation of synovitis had only recently occurred. More acute disease in AS may have been reflected by the greater proportion of $\mathrm{Ki} 67+$ cells as compared with RA. Secondly, the blind needle biopsy technique might have resulted in significant sampling variation, though an attempt was made to minimise this by obtaining biopsy specimens from a similar area on the suprapatellar pouch of the knee. ${ }^{13}$ Finally, a semiquantitative scoring method was adopted as it was felt that this more accurately reflected the observed changes in the presence of marked inter biopsy and intrabiopsy variation. It is accepted however, that this method may not be sensitive to small quantitative differences between the disorders.

Histological examination of the synovial membrane in AS is reported to show appearances similar to those found in RA. ${ }^{1-3}$ Our observations were in general agreement with these reports and showed a diffuse cellular infiltrate with increased vascularity in all diagnostic groups.

The lymphocytic infiltrate within the synovial membrane in RA and AS is dominated by T cells. There is general agreement that in untreated RA synovial $\mathrm{T}$ cell subpopulations show an increased number of CD4+ cells compared with CD8+ cells, the ratio varying from between $5: 1$ to over $10: 1{ }^{21}{ }^{22}$ This increased ratio in RA synovial membrane was confirmed in the present study. In contrast, we found that in AS and oligoarthritis CD8+ cells occurred with approximately the same frequency as CD4+ cells in nearly all biopsy specimens. Increased numbers of CD4+ cells relative to CD8+ cells in RA were most marked in the perivascular regions; no such regional variations were found in AS, however.

A study by Lindblad et al describing the immunohistological features of synovitis from various arthropathies reported that the infiltrate was similar in all groups and was characterised by a heavy $T$ cell infiltrate predominantly of the 'helper' cell type. ${ }^{23}$ Numbers of patients in the study were small, 
however, with only three patients having an HLAB27 associated arthropathy and none having ankylosing spondylitis as in the present study. Another report of $T$ lymphocyte subpopulations in $R A$, HLA-B27 associated oligoarthritis, and normal controls detailed differences between the two inflammatory conditions as regards synovial fluid $\mathrm{T}$ cell populations, although no synovial biopsy material was available from the B27 group. ${ }^{24}$

Current evidence supports functional and phenotypic heterogeneity within the CD4+ lymphocytic population with both suppressor/inducer and helper/ inducer subpopulations. ${ }^{8} 16$ WR16 is a monoclonal antibody which binds to the p220 component of the leucocyte common antigen, indicating that this antibody has the same specificity as other CD45R clustered antibodies. It reacts with $48 \%$ of CD4+ lymphocytes in normal tonsil tissue ${ }^{16}$ and in vitro identifies a CD4+ suppressor/inducer subpopulation. We have previously shown a relative deficiency of CD4+/WR16+ cells in RA synovial membrane and this has led to the concept that a defect in suppressor activity may be responsible for the immunological abnormalities observed in RA. ${ }^{25}$ Other studies using another CD45R antibody (2H4) have reported similar findings. ${ }^{26}$

Our study was unable to show significant differences between RA and AS as regards CD4+ lymphocytic subpopulations, and in both disorders UCHL1 + cells predominated to the exclusion of WR16+ $(\mathrm{CD} 45 \mathrm{R}+)$ cells. We were therefore unable to explain the different $\mathrm{CD} 4+/ \mathrm{CD} 8+$ ratios observed in RA and AS on the basis of an alteration in UCHL1+/CD45R + cell subpopulations. Recent experimental evidence from our laboratory indicates that after activation by mitogen of antigen $\mathrm{CD} 4+$ / CD45R + cells decrease membrane expression of CD45R antigen (A M Nesbitt, unpublished data). This indicates that absence of CD45R + cells within RA and AS synovial membrane may be the consequence of generalised $T$ cell activation rather than the preferential extravasation of a particular lymphocyte subset.

Synovial infiltrate in early rheumatic disease has received little attention and it is unclear whether the changes observed in chronically inflamed synovial tissue reflect the underlying aetiopathology or not. ${ }^{27} 28$ Study of early synovial biopsy material from AS has not been reported, but a recent report has suggested that in acute reactive arthritis, a disorder related to AS, chlamydial antigen can be identified within the synovium. ${ }^{29}$ Certain infectious agents can stimulate CD8+ cell production, ${ }^{8}$ and these cells can outnumber CD4+ cells in some inflammatory situations, including, for example, occular infections with Chlamydia trachomatis. ${ }^{30}$
The increased numbers of $\mathrm{CD} 8+$ in AS relative to RA observed in our biopsy material may similarly indicate a local reaction to products of an infectious process.

It is generally believed that the prime lesion in AS occurs at or near the enthesis, ${ }^{31}$ and the few histological studies of the enthesis in early disease point to an inflammatory lesion of the subchondral bone. ${ }^{32}$ Clinical observation suggests that synovitis and enthesitis are closely linked, and the synovial lesion observed in AS may alternatively represent a secondary response to an inflammatory lesion within surrounding tissue.

In conclusion, we have compared the immunohistological features of the synovial membrane in RA, AS, and oligoarthritis. The marked difference between CD4+ and CD8+ cell numbers found in RA was not observed in AS or oligoarthritis, where cell numbers were equal. The proposed immunoregulatory defect resulting in subset imbalance in $\mathrm{RA}$ does not appear to be operative in AS or oligoarthritis.

\section{References}

1 Cruikshank B. Histopathology of diarthrodial joints in ankylosing spondylitis. Ann Rheum Dis 1951; 10: 393-404.

2 Julkunen K. Synovial inflammatory cell reaction in chronic arthritis. Acta Rheumatologica Scandinavica 1966; 12: 188-96.

3 Wagner $T$. The microscopic appearances of synovial membranes in peripheral joints in ankylosing spondylitis. Rheumatologica 1970; 8: 209-15.

4 Revell P A, Mayston V. Histopathology of the synovial membrane of peripheral joints in ankylosing spondylitis. Ann Rheum Dis 1982; 41: 579-86.

5 Duke O, Hobbs S, Poulter L W, Panayi G S. An immunohistological analysis of the synovial membrane in ankylosing spondylitis. Arthritis Rheum 1985; 28: S94.

6 Wilkinson M, Bywaters E G L. Clinical features and course of ankylosing spondylitis. Ann Rheum Dis 1958; 17: 209-28.

7 McGuigan L E, Geczy A F, Edmonds J P. The immunopathology of ankylosing spondylitis-a review. Semin Arthritis Rheum 1985; 15: 81-105.

8 Romain P L. Schlossman S F. The T cell circuit: clinical and biological implications. Adv Intern Med 1986; 31: 1-16.

9 Ropes M W. Bennett G A. Cobb S, Jacox R. Jessar R A. 1958 revision of diagnostic criteria for rheumatoid arthritis. Arthritis Rheum 1959; 2: 16-20.

10 Bennet P H, Burch T A. Population studies of the rheumatic diseases. Amsterdam: Excerpta Medica, 1968: 456-7.

11 Moll J M H, Haslock I, Macrae I F, Wright V. Associations between ankylosing spondylitis, psoriatic arthritis. Reiters disease, the intestinal arthropathies, and Behçet's syndrome. Medicine (Baltimore) 1974; 53: 343-64.

12 Gregg E O, Al-Saffar N, Jones D B, Stevenson F K, Smith J L. Immunoglobulin negative follicle centre cell lymphoma. $\mathrm{Br} J$ Cancer 1984; 50: 735-44.

13 Walters M T, Smith J L. Moore K. Evans P R, Cawley M I D. An investigation of the action of disease modifying antirheumatic drugs on the rheumatoid synovial membrane: reduction in T lymphocyte subpopulations and HLA-DP and DQ antigen expression after gold or penicillamine therapy. Ann Rheum Dis 1987; 46: 7-16.

14 McMichael A J, ed. Leucocyte typing III. London: Oxford University Press, 1987. 
15 Smith S H, Brown M H, Rowe D, Callard R E, Beverley P C L. Functional subsets of human helper-inducer cells defined by a new monoclonal antibody, UCHL1. Immunology 1986; 58: 63.

16 Moore K, Nesbitt A M. Functional heterogeneity of CD4+ T lymphocytes: two subpopulations with counteracting immunoregulatory functions identified with the monoclonal antibodies WR16 and WR19. Immunology 1987; 61: 159-65.

17 Abo T, Balch CM. A differentiation antigen of human NK and $\mathrm{K}$ cells identified by a monoclonal antibody (HNK1). J Immunol 1981; 127: 10-24.

18 Parham P, Barnstable C J, Bodmer W F. Use of a monoclonal antibody (W6/32) in structural studies of HLA-A, B, C antigens. J Immunol 1979; 123: 342-9.

19 Moore K, Cooper S A, Jones D B. Use of monoclonal antibody WR18 identifying the CD37 gp 40-45 antigen complex in the diagnosis of B lymphoid malignancy. J Pathol 1987; 152: 13-21.

20 Gerdes J, Schwab U, Lemke H, Stein H. Production of a mouse monoclonal antibody reactive with a human nuclear antigen associated with cell proliferation. Int J Cancer 1983; 31: 13-20.

21 Duke O, Panayi G S, Janossy G, Poulter L W. An immunohistological analysis of lymphocyte subpopulations and their microenvironment in the synovial membranes of patients with rheumatoid arthritis using monoclonal antibodies. Clin Exp Immunol 1982; 49: 22-30.

22 Meijer C J L M, de Graaff C B, Lafeber G J M, Cats A. In situ localisation of lymphocyte subsets in synovial membranes of patients with rheumatoid arthritis with monoclonal antibodies. $J$ Rheumatol 1982; 9: 359-65.

23 Lindblad S, Klareskog L, Hedfors E, Forsum U, Sundstrom C. Phenotypic characterisation of synovial tissue cells in situ in different kinds of synovitis. Arthritis Rheum 1983; 26: 1321-32.
24 Jahn B, Burmester G R, Gramatzki M, Weseloh G, Stock P, Kalden J R. Intraarticular T lymphocytes in monoarticular and oligoarticular inflammatory joint disease. $J$ Rheumatol 1986; 13: 254-8.

25 Moore K, Walters M T, Garvey E M, Cawley M I D, Smith J L. Immunoregulatory subsets of CD4+ lymphocytes within rheumatoid synovial membranes and the effect of therapy with disease modifying drugs. $\mathrm{Br} J$ Rheumatol 1987; 26: S55.

26 Kingsley G, Pitzalis C, Panayi G. Distribution of the helper/ inducer ( $\mathrm{T} 4+4 \mathrm{~B} 4+$ ) and suppressor/inducer $(\mathrm{T} 4+2 \mathrm{H4}+)$ subsets in rheumatoid arthritis. Br J Rheumatol 1986; 25: S65.

27 Schumacher H R, Kitridou R C. Synovitis of recent onset. A clinicopathologic study during the first month of disease. Arthritis Rheum 1972; 15: 465-85.

28 Konttinen Y T, Bergroth V, Nordström D, et al. Cellularimmunohistopathology of acute, subacute, and chronic synovitis in 0 rheumatoid arthritis. Ann Rheum Dis 1985; 44: 549-55.

29 Keat A, Thomas B, Dixey J, Osborn M, Sonnex C, TaylorRobinson D. Chlamydia trachomatis and reactive arthritis: the missing link. Lancet 1987; i: 72-4.

30 Dawson CR. Eye disease with chlamydial infections. In: Oriel D, Ridgeway G, Schachter J, Taylor-Robinson D, Ward M, eds. O Chlamydial infections. Cambridge: Cambridge University Press, 1986; 135-44.

31 Ball J. Enthesopathy of rheumatoid and ankylosing spondylitis. Ann Rheum Dis 1971; 30: 213-23.

32 Shichkawa $K$, Tsujioto $M$, Nishioka J, Nishibayashi $Y$, Matsumoto K. Histopathology of early sacroiliitis and enthesitis in ankylosing spondylitis. In: Ziff $\mathrm{M}$, Cohen S B, eds. Advances in inflammation research. Vol 9. The spondylarthropathieg. New York: Raven Press, 1985: 15-24. 